\title{
The Effect of Chronic Furosemide Administration on Urinary Calcium Excretion and Calcium Balance in Growing Rats
}

\author{
BARRY L. WARSHAW.'"' SUDHIR K. ANAND, ALICE KERIAN. ANI) ELLIN LIEBERMAN \\ Department of Pediatrics and Division of Nephrologi: Childrens Hospital of Los Angeles, and University of Southern \\ California, Los Angeles. California. USA
}

\begin{abstract}
Summary
This study was designed to determine the calciuretic effect of furosemide and its impact upon calcium balance during chronic (25 days) furosemide administration to growing rats. Experiments were performed on 18 six-wk-old rats. Nine animals received furosemide, and 9 served as controls. The administration of furosemide in a dose of $\mathbf{4 0} \mathrm{mg}$ resulted in a significant increase in calcium excretion in the treated group; urinary calcium excretion almost doubled that of the controls during the first 24 -hr collection $(3.74 \pm 0.44 \mathrm{mg}$ in the treated animals compared with $1.90 \pm 0.15$ $\mathrm{mg}$ in the controls; $\boldsymbol{P}<\mathbf{0 . 0 5}$ ). The average daily urinary calcium excretion during each of four subsequent 6-day periods remained approximately three-fold higher in animals which received furosemide compared with controls ( $P<0.001$ for each 6-day period). The furosemide-induced increase in urinary calcium excretion did not diminish with time. Sodium excretion did not significantly increase either acutely or chronically in response to furosemide. Daily urinary volume increased approximately 40 to $60 \%$ in the furosemide-treated group compared with that of the controls ( $P$ $<0.001)$. The cumulative calcium balance in the control group exceeded by $7 \%$ that of the furosemide-treated animals $12696.3 \pm$ $20.8 \mathrm{mg}$ versus $2518.6 \pm 20.1 \mathrm{mg}(P<.001) \mid$.

The findings indicate that distal nephron compensatory mechanisms effecting sodium conservation following furosemide do not result in similar conservation of calcium. Calcium balance may be deleteriously affected.
\end{abstract}

\section{Speculation}

The long-term effects of furosemide on calcium homeostasis in man are not known. This study in rats suggests that furosemide may have deleterious effects on calcium homeostasis. Similar effects in humans, particularly growing children, may result in decreased calcium balance and bone demineralization.

Furosemide, a potent natriuretic agent, acutely increases urinary calcium excretion along with urinary sodium excretion $(2,6,17)$. Studies on the mechanism of the acute (1-to 2-hr) calciuresis have shown that furosemide inhibits solute transport in the ascending limb of the loop of Henle, where calcium absorption appears to be coupled with sodium transport (2). In contrast, in the distal tubule, sodium and calcium transport can be dissociated: thiazide diuretics, which inhibit sodium reabsorption in the distal tubule. have little to no acute calciuretic effect $(2,3,7,8)$.

Furosemide is being used on a chronic basis, primarily for its natriuretic action, for the treatment of many clinical conditions. including severe hypertension (4). chronic renal insufficiency of varied etiologies (12,15), and bronchopulmonary dysplasia of the newborn (11, 13). The acute calciuretic action of furosemide has been of benefit in the treatment of acute hypercalcemia (14, 17): however, little human or animal information exists on the chronic (i.e. more than $1 \mathrm{wk}$ ) effects of furosemide on calcium homeostasis. This study was designed to determine the calciuretic effect of furosemide and its impact upon calcium balance during chronic ( 25 days) furosemide administration to growing rats.

\section{MATERIALS AND METHODS}

Experiments were performed on 18 six-wk-old Sprague-Dawley albino rats which weighed 188 to $202 \mathrm{~g}$. Nine animals received furosemide, and 9 served as controls. The rats were housed in individual metabolic cages (Hoeltge/Acme. Inc.) to permit separate collections of urine and stool. The animals were allowed free access to distilled water. Purina laboratory chow was provided in a feeding chamber to prevent significant food contamination of urine and stool collections. The chow was prepared once daily as a paste by mixing $15 \mathrm{~g}$ of powdered chow with $25 \mathrm{~g}$ of distilled water. Urine and stool collections were performed once daily: the walls of the metabolic collection chamber were rinsed daily with distilled water to recover any dried urinary sediment. Before rinsing, 24-hr urinary volume was measured and recorded. At the beginning of the daily collection period. I cc of $6 N$ hydrochloric acid was added to the urine collection bottle to prevent precipitation of calcium salts. Daily urine collections were analyzed separately, whereas stool specimens were pooled for 2- to 4-day periods. All specimens were frozen $\left(-20^{\circ} \mathrm{C}\right)$ before chemical determinations which were performed at the conclusion of the experiment. The animals were weighed at weekly intervals. Baseline and weekly serum samples were obtained from each animal by severing the tip of the tail and pipeting $1 \mathrm{cc}$ of whole blood.

After a 4-day equilibration period. metabolic balance studies were begun. Baseline urine and stool collections were performed for 2 days before the 25-day treatment period. Each of the 9 treated animals then received furosemide which was added to the food once daily in a dose of $40 \mathrm{mg} /$ day for the following 25 days. The powdered drug was thoroughly mixed with the food. The animals were pair fed throughout the experiment, although alterations in the amount of food were unnecessary because the diet was completely consumed by each animal. The dose of furosemide selected was based on the minimal dosage necessary to increase acutely the mean 24-hr urine volume by $50 \%$ or more compared with the $24-\mathrm{hr}$ baseline volume. Neither sodium nor potassium dietary supplements was utilized during this study.

At the end of the experimental phase. the animals were anesthetized with ether and exsanguinated via the inferior vena cava. The sera were frozen and saved for chemical analyses.

Chemical determinations were performed as follows: calcium was measured by the cresolpthalein-complexone spectrophotometric method (Worthington Diagnostics: Gilford $300 \mathrm{~N}$ Spectrophotometer) (1), phosphorus was measured by ferrous ammonium sulfate reduction of phosphomolybdate magnesium according to the method of Gindler and Heth (10) using calmagite. sodium. and potassium by flame photometry. Analyses were performed on 
serum and urine specimens and, after ashing, on stool and food specimens. Ashing of stool and food was accomplished by heating at $800^{\circ} \mathrm{C}$ for $24 \mathrm{hr}$; the ash specimens were then dissolved in I cc of 0.75 normal nitric acid per $100 \mathrm{mg}$ ash weight in preparation for analysis.

The food was analyzed in 9 batches, and the mean electrolyte composition was as follows: sodium, $0.30 \%$, potassium, $0.36 \%$; calcium, $1.23 \%$ : magnesium, $0.21 \%$; and phosphorus, $1.03 \%$.

Calcium balance was calculated for 2- to 4-day intervals corresponding to stool collections by subtracting urinary calcium plus stool calcium from the total calcium in the diet during that period.

Recovery experiments were performed on urine and stool. The results of recovery of electrolytes added to urine (mean of 10 determinations \pm S.E.) were: sodium, $98.0 \pm 0.3 \%$ : potassium. 99.2 $\pm 0.1 \%$ : calcium, $101.4 \pm 1.9 \%$; magnesium. $98.6 \pm 0.6 \%$; and phosphorus, $99.5 \pm 0.6 \%$. Recovery of calcium added to stool (mean of 12 determinations \pm S.E.) was $99.9 \pm 0.8 \%$.

Statistical differences were assessed by the unpaired Student $t$ test.

\section{RESULTS}

The average daily urinary electrolyte excretion and urinary volume (mean \pm S.E) are presented in Table $I$ as follows: a 2 -day baseline period. a single day collection at the initiation of furosemide, and 4 six-day periods while continuing $40 \mathrm{mg} /$ day of furosemide.

The 2-day baseline urinary calcium excretion did not differ between the 2 groups. The administration of furosemide resulted in a significant increase in calcium excretion in the treated group: urinary calcium excretion almost doubled that of the controls during the first $24-\mathrm{hr}$ collection $(3.74 \pm 0.44 \mathrm{mg}$ in the treated animals compared with $1.90 \pm 0.15 \mathrm{mg}$ in the controls: $P<0.05$ ). The average daily urinary calcium excretion during each of the subsequent 6-day periods remained approximately three-fold higher in animals which received furosemide compared with controls $(P<0.00$ I for each period). The furosemide induced increase in urinary calcium excretion did not diminish with time.

Baseline urinary sodium excretion did not differ between the 2 groups; sodium excretion did not significantly increase either acutely or chronically in response to furosemide. The failure of urinary sodium excretion to increase acutely had been observed in several preliminary trials using doses of furosemide as high as $100 \mathrm{mg} /$ day.

Both urinary magnesium and urinary phosphorus excretion showed a slight but statistically significant increase in the furosemide-treated group compared with the control group during each of the six-day periods $(P<0.05)$. The magnitude of these increases did not exceed $20 \%$. Potassium excretion did not differ between the 2 groups during the baseline period nor during the first day of furosemide: the excretion did significantly increase in the treatment group during the first and second 6 -day periods $(P<0.05)$ but not during the final two 6-day periods.

Daily urinary volume increased approximately 40 to $60 \%$ in the treated group compared with that of the controls $(P<0.001)$. beginning on the first day of furosemide administration and persisting throughout the study.

Results of serum electrolyte determinations are shown in Table 2. Serum calcium and sodium concentrations did not differ between the 2 groups. Serum magnesium was slightly higher in the furosemide-treated animals as compared with the controls; this difference reached significance on days 13 and 20 but not on day 26. Serum phosphorus concentration was similar between groups except on day 20 when the level was slightly lower in the treated animals. Serum potassium was consistently lower in the furosemide group, although the difference was only transiently significant.

Calcium balance is shown in Figure 1. The balance was strongly

Table 1. Daily urinary electrolyte excretion and urinary volume in furosemide-treated group (F) and controls (C)

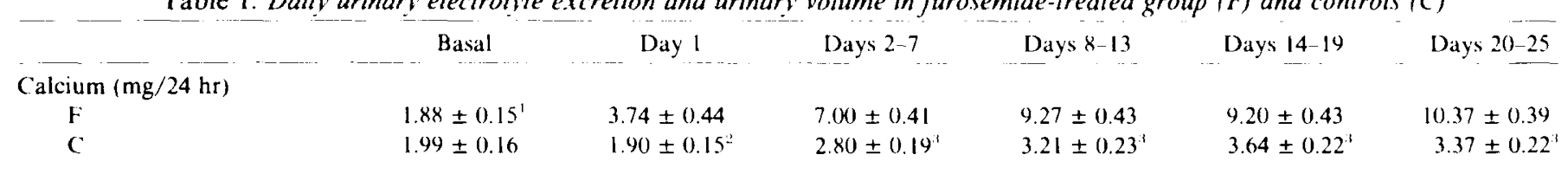

Sodium $(\mathrm{mEq} / 24 \mathrm{hr})$

$\begin{array}{lllllll}\text { F } & 1.64 \pm 0.08 & 2.01 \pm 0.09 & 1.91 \pm 0.05 & 1.90 \pm 0.03 & 1.87 \pm 0.03 & 1.89 \pm 0.02 \\ \text { C } & 1.65 \pm 0.06 & 1.73 \pm 0.11 & 1.86 \pm 0.03 & 1.94 \pm 0.04 & 2.04 \pm 0.03^{2} & 1.84 \pm 0.05\end{array}$

Magnesium (mg/24 hr)
F
$6.65 \pm 0.44$
$7.09 \pm 0.38$
$8.62 \pm 0.35$
$7.59 \pm 0.20^{2}$
$8.66 \pm 0.31$
$7.83 \pm 0.18^{\prime \prime}$
$8.87 \pm 0.31$
$8.24 \pm 0.16^{2}$
$9.10 \pm 0.26$
$6.42 \pm 0.37$
$8.23 \pm 0.17^{2}$

Phosphorus (mg/24 hr)

F

(:

Potassium (mEq/24 hr)
$17.1 \pm 1.0$

$18.7 \pm 1.3$
$19.8 \pm 0.6$

$16.8 \pm 0.7$
$17.5 \pm 0.6$

$15.5 \pm 0.5$
$18.3 \pm 0.6$

$10.0 \pm 0.5$
$18.1 \pm 0.6$

$15.3 \pm 0.6$
F.

C

Volume (cc/24 hr)

\section{Volume (cc/24 hr)}

\section{F}

C

$12.2 \pm 0.3$

$14.5 \pm 0.6^{2}$

$23.1 \pm 1.8$

$14.8 \pm 0.7^{1}$
$24.8 \pm 1.4$

$14.5 \pm 0.4^{3}$

$23.7 \pm 0.8$

$16.3 \pm 0.4$
$26.5 \pm 1.2$

$18.6 \pm 0.6^{\prime \prime}$

$26.4 \pm 0.8$

$17.5 \pm 0.9^{1}$

'Mean \pm S.E.

"The baseline period represents the average of 2 collection days; Day 1 is the first day of furosemide treatment: Days 2 through 25 are divided into 6-day periods; average daily excretion during each period is shown. Statistical differences between groups (unpaired Student $t$ test); $P<0.05$.

${ }^{3}$ Statistical differences between groups (unpaired $t$ test); $P<0.001$. 
Table 2. Serum electrolvte values in furosemide treated group $(F)$ and controls $(C)$

\begin{tabular}{|c|c|c|c|c|c|}
\hline \multicolumn{6}{|c|}{ 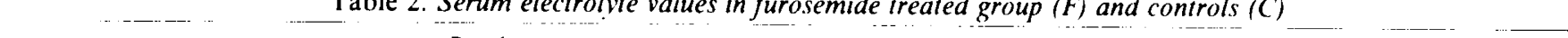 } \\
\hline & Basal & Day 7 & Day 13 & Day 20 & Day 26 \\
\hline \multicolumn{6}{|c|}{ Calcium (mg/dl) } \\
\hline$F$ & $10.13 \pm 0.11^{1}$ & $10.87 \pm 0.26$ & $10.71 \pm 0.14$ & $10.40 \pm 0.14$ & $9.82 \pm 0.09$ \\
\hline C & $10.38 \pm 0.15$ & $10.59 \pm 0.16$ & $10.57 \pm 0.13$ & $10.49 \pm 0.09$ & $9.95 \pm 0.15$ \\
\hline \multicolumn{6}{|c|}{ Sodium (mEq/liter) } \\
\hline $\mathrm{F}$ & $143.0 \pm 0.5$ & $147.9 \pm 1.4$ & $140.6 \pm 0.9$ & $143.1 \pm 2.4$ & $152.1 \pm 1.3$ \\
\hline c & $144.6 \pm 2.0$ & $146.1 \pm 1.1$ & $142.2 \pm 1.1$ & $145.1 \pm 0.5$ & $151.7 \pm 1.7$ \\
\hline \multicolumn{6}{|c|}{ Magnesium (mg/dl) } \\
\hline $\mathrm{F}$ & $1.92 \pm 0.09$ & $2.14 \pm 0.03$ & $2.12 \pm 0.06$ & $2.30 \pm 0.06$ & $2.56 \pm 0.11$ \\
\hline c & $1.76 \pm 0.04$ & $2.13 \pm 0.05$ & $1.76 \pm 0.06^{2}$ & $2.10 \pm 0.06^{3}$ & $2.35 \pm 0.06$ \\
\hline \multicolumn{6}{|c|}{ Phosphorus (mg/dl) } \\
\hline $\mathrm{F}$ & $8.87 \pm 0.40$ & $7.02 \pm 0.16$ & $7.02 \pm 0.18$ & $6.02 \pm 0.11$ & $6.82 \pm 0.20$ \\
\hline C & $8.43 \pm 0.27$ & $7.13 \pm 0.26$ & $6.58 \pm 0.18$ & $7.00 \pm 0.31^{3}$ & $6.40 \pm 0.22$ \\
\hline \multicolumn{6}{|c|}{ Potassium ( $\mathrm{mEq} / \mathrm{liter}$ ) } \\
\hline $\mathrm{F}$ & $6.0 \pm 0.5$ & $4.5 \pm 0.6$ & $5.1 \pm 0.1$ & $4.7 \pm 0.1$ & $4.5 \pm 0.2$ \\
\hline C & $5.3 \pm 0.2$ & $5.7 \pm 0.1$ & $5.4 \pm 0.1^{3}$ & $5.4 \pm 0.2^{3}$ & $4.9 \pm 0.2$ \\
\hline
\end{tabular}

${ }^{\prime}$ Mean \pm S.E.

${ }^{2} S t a t i s t i c a l$ differences between groups (unpaired Student $t$ test): $P<0.001$.

Statistical differences between groups (unpaired Student $t$ test): $P<0.05$.

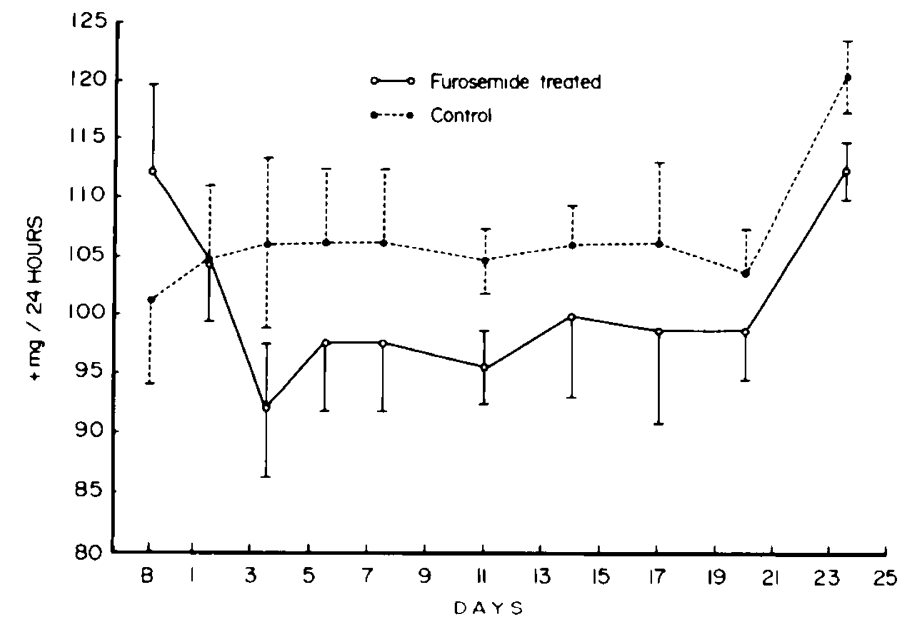

Fig. I. Calcium balance in furosemide-treated and control animals. The average daily balance for each 2 - to 4-day collection period is shown. $B$, 2-day baseline period. Bars, I S.E.

positive in both groups of animals throughout the experiment. However, the balance in the furosemide group became significantly less positive as compared with that of the controls by the third and fourth treatment days and remained less positive throughout the experiment. The cumulative calcium balance in the control group exceeded by $7 \%$ that of the furosemide-treated animals (2696.3 \pm 20.8 versus $2518.6 \pm 20.1: P<0.001)$.

Body weights in the furosemide treated and control groups increased from $200.4 \pm 1.5$ and $202.3 \pm 1.8 \mathrm{~g}$ (not significant), respectively, during the baseline period to $233.8 \pm 2.2$ and 245.1 $\pm 3.3(P<0.05)$, respectively, on day 25 .

\section{DISCUSSION}

The acute calciuretic effect of furosemide has been effectively utilized in the treatment of hypercalcemia in children and adults $(14,17)$. To sustain furosemide-induced hypercalciuria throughout treatment and to avoid dehydration. therapy is usually accompanied by high maintenance fluids and supplemental sodium chloride. In the absence of supplemental sodium, urinary sodium excretion eventually returns to pretreatment levels despite continued furosemide therapy, although total body sodium has been reduced (16). The fate of urinary calcium excretion under these conditions is unclear. Whereas furosemide-induced urinary calcium excretion closely parallels sodium excretion in acute experi- ments, documentation of the persistence of this relationship on a chronic basis is not available.

Our data in rats have demonstrated that furosemide-induced hypercalciuria may persist for as long as 25 days despite the absence of increased urinary sodium excretion. Hypercalciu ria did not diminish with time and occurred without sodium supplementation. Urinary calcium excretion in the furosemide-treated group was three times that of the controls. Moreover, the calcium balance in animals receiving furosemide was significantly less positive than that of the controls, suggesting that furosemide-induced hypercalciuria did not result in compensatory increases in intestinal calcium absorption. Serum phosphorus concentration was similar between groups on 3 of 4 determinations, suggesting that hypercalciuria was not mediated by hypophosphatemia.

The marked dissociation of urinary sodium from urinary calcium excretion observed in this study contrasts with the usual parallel excretion of these ions. Furosemide has been shown to exert a similar effect on both sodium and calcium reabsorption in the asending limb of the loop of Henle $(2,7)$. Moreover, other agents $(2,6-8)$ affecting sodium reabsorption in the loop of Henle, as well as in the proximal tubule, also induce parallel changes in calcium reabsorption at these sites. These observations have led to the conclusion that the reabsorption of sodium and calcium in these nephron segments is linked (2). In contrast. inhibition of sodium reabsorption in the distal tubule, most notably with thiazides, may not produce parallel inhibition of calcium reabsorption (2, 3, 7, 8). Handling of these ions in the distal nephron thus appears to be via separate mechanisms.

In this study, sodium excretion failed to rise significantly either acutely or chronically, despite significant elevations in calcium excretion and in urinary volume. These findings may be related to the administration of furosemide with food which may not have been consumed at a constant rate during the 24-hr urine collection. Thus a period of time during which compensatory renal sodium reabsorption occurred may explain the lack of net increase in urinary sodium excretion. Alternatively, furosemide-induced inhibition of sodium reabsorption in the ascending limb of the loop of Henle may have been offset by increased reabsorption in more distal nephron segments unaffected by the drug. This latter interpretation is supported by the work of Antoniou et al. (2) which demonstrated that the increase in urinary calcium excretion above that of sodium excretion after acute administration of furosemide was eliminated by thiazide blockade of sodium reabsorption in the distal tubule. Our findings emphasize that distal compensatory mechanisms effecting sodium conservation after furosemide do not result in similar conservation of calcium on either an acute or a chronic basis.

The mean body weight of the furosemide-treated animals was 
significantly less than that of the controls at the end of the experimental period. The reasons for the decreased weight could not be ascertained in this study. Dietary intake was identical in the two groups. Both urinary sodium excretion and serum sodium concentrations were similar in treated and control animals. Differences in extracellular fluid volume thus seem unlikely to account for the weight discrepancy. It is possible that the less positive calcium balance in the treated group in some way is related to the impaired growth.

Studies of the effects of furosemide on calcium homeostasis in man will be necessary to assess the relevance of our findings in rats to the use of furosemide clinically. Evidence exists that furosemide-induced hypercalciuria may persist during chronic administration in man. Hufnagle et al. (11) reported four neonates who developed renal calcifications after furosemide administration for at least 27 days. Coe et al. (5) found increased urinary calcium excretion and elevated serum parathyroid hormone levels in normal adult subjects given furosemide with sodium supplementation for 9 days. In contrast, Toft and Roin (18) administered furosemide to adipose volunteers who developed acute hypercalciuria, but by the fourth day of continuous furosemide treatment, urinary calcium excretion had become normal. Similarly, hypercalciuria after furosemide did not persist beyond the first day of treatment in a group of hypoparathyroid patients, although cessation of hypercalciuria coincided with the occurrence of hypocalcemia in these subjects (9).

In conclusion, our findings in rats demonstrate that hypercalciuria may persist during chronic furosemide treatment and that calcium balance may be deleteriously affected. Available studies do not sufficiently clarify the long-term effects of furosemide on calcium homeostasis in man. In patients with marginal calcium reserves and increased needs, such as sick neonates, or in those receiving high doses of furosemide for long periods of time, evaluation of the effects of chronic furosemide on calcium homeostasis is warranted.

\section{REFERENCES AND NOTES}

1. Annino, J. S.: Clinical (hemistry. Principles and Procedures. p. 202 (Little Brown \& (o.. Boston, 1976).

2. Antoniou. L. D., Eisner. G. M., Slotkoff, L. M., and Lilienfield, L. S.: Relationship between sodium and calcium transport in the kidney. J. Lab. Clin. Med.. 74 $410(1969)$.

3. Brickman. A. S., Massry. S. G., and Coburn. J. W.: Changes in serum and urinary calcium during treatment with hydrochlorothiazide: studies on mechanisms. J. Clin. Invest., 51: 945 (1972).

4. Cantarovich F Benedetti, L. Fernandez I C. Chena, C.. Castro, L.. Galli, C. J.. Perez Loredo, J.. Locatelli, A.. and Tizado, J.: High doses of furosemide and sodium in hypertension. Nephron. 12: 133 (1974).

5. Cire, F. L.. Canterbury, J. M.. Firpo. J. J., and Reiss. E.: Evidence for secondary hyperparathyroidism in idiopathic hypercalciuria. J. Clin. Invest., 52: 134 (1973).

6. Duarte, C. G.: Effects of Ethacrynic Acid and Furosemide on Urinary Calcium. Phosphate and Magnesium. Metabolism. 17: 867 (1968)

7. Edwards, B. R. Baer. P. G., Sulton, R. A. L., and Dirks, J. H.: Micropuncture Study of Diuretic Effects on Sodium and Calcium Reabsorption in the Dog Nephron. J. ("lin. Invest., 52: 2418 (1973).

8. Eknoyan, G.. Suki, W. N.. and Martinez-Maldonado, M.: Effect of diuretics on urinary excretion of phosphate. calcium and magnesium in thyroparathyroid ectumized dogs. J. Lab. Clin. Med.. 76: 257 (1970)

9. (jabow. P. A.. Hanson. T. J.. Popovtzer. M. M.. and Schrier, R. W.: Furosemideinduced reduction in ionized calcium in hypoparathyroid patients. Ann. Intern. Med.. 86: 579 (1977).

10. Gindler, E. M., and Heth. D. A.: Colorimetric determination with bound "calmagite" of magnesium in human blood serum. Clin. (hem.. 17:662 (1971).

11. Hufnagle, K., Penn. D., and Williams, P.: Renal calcifications: a complication of long-term high-dose furosemide. J. Pediatr., 93: 314 (1978).

12. Levin. N. W.: Furosemide and ethacrynic acid in renal insufficiency. Med. (Clin N. Am.. 55: 107 (1971).

13. Moylan, F. M. B., O'Connell, K. C.. Todres, I. D., and Shannon, D. C.: Edema of the Pulmonary Interstitium in Infants and Children. Pediatrics, 55: 783 (1975).

14. Najjar, S. S., Aftimos. S. F., and Kurani, R. F.: Furosemide therapy for hypercalcemia in infants. J. Pediatr., 81: 1171 (1972).

15. Silverberg. D. S.. Ulan. R. A., Baltzan, M. A., and Baltzan. R. B.: Experiences with high doses of furosemide in renal disease and resistant edematous states. (an. Med. Assoc. J.. 103: 129 (1970).

16. Steven. K. E., and Skadhauge, E.: Sodium chloride depletion and renal concentrating ability during chronic administration of thiazide (centyl) and furosemide (lasix) to the normal rat. Acta Pharmacol. Toxicol., 27: 1 (1969).

17. Suki, W. N., Yium. J. J., Von Minden, M., Saller-Hebert, C., Eknoyan, G., and Martinez-Maldonado. M.: Acute treatment of hypercalcemia with furosemide N. Engl. J. Med., 283: 836 (1970).

18. Toft. $\mathrm{H}$., and Roin $\mathrm{J}$ : Effect of furosemide administration on calcium excretion Br. Med. J., I: 437 (1971)

19. The authors are very grateful to Dr. Jack Coburn. Professor of Medicine, UCLA School of Medicine and Head, Division of Nephrology. Veterans Administration Hospital-Wadsnorth, Los Angeles, CA 90073, for his invaluable help with this research project. Our thanks to Diane Casteel for her excellent secretarial help.

20. Requests for reprints should be addressed to: Dr. Barry L. Warshaw, Department of Pediatrics, Emory University School of Medicine, 69 Butler Street, Atlanta. GA 30303 (USA).

21. This research was supported by Biomedical Research Support Grant PHS S07RR05469-15. Dr. Warshaw was supported in part by The Kidney Foundation of Southern California.

22. Received for publication September 17, 1979

23. Accepted for publication January 11, 1980. 